\title{
Employees' Discernment of Workforce Diversity and Its Effect on Job Satisfaction in a Public Service Department
}

\author{
Wiza Munyeka
}

Department of Business Management, University of Limpopo (Turf loop Campus), Private Bag 1106. Sovenga, 0727. South Africa Email: masterwiza2000@yahoo.com

\section{Doi:10.5901/mjss.2014.v5n15p37}

\begin{abstract}
In South Africa, much has been said and legislated in terms of enhancing workforce diversity of organizations. Workforce diversity issues are now considered important and are projected to become even more important in the future due to increasing differences in terms of age, gender, race or origin in the organization. Organizations need to focus on diversity and look at ways to become totally inclusive organizations because diversity has the potential of yielding greater job satisfaction and competitive advantages. The need to understand diversity is also driven by women and younger workers in the workplace. The current study focuses on the employees' discernment of workforce diversity and its effect on job satisfaction. A sample of 90 employees was used in the study. The data was collected by means of a questionnaire which consisted of closed ended questions on a Likert-Scale. Statistical analysis was applied to the quantitative data obtained. Seven factors (age, marital status, ethnicity, income levels, period of service, professional qualification and job title) were investigated. The results indicated that five of the factors could have predictive effect on employee commitment to work. However, employee commitment was not significantly affected by the factor of gender.
\end{abstract}

Keywords: Age; Cultural knowledge; ethnicity; Gender; Disability; job satisfaction; Marital status; Sexual orientation; Tenure; workforce diversity

\section{Introduction}

This study focuses on one of the most important and broad-based challenges currently facing organizations in adapting to people who are different. The term used for describing this challenge is workforce diversity. Whereas globalisation focuses on differences between people from different countries, workforce diversity addresses differences among people within a given country (Strydom, 1998).

According to Meyer (1999), most South African employees experience a lack of job satisfaction resulting in a low level of employee commitment that, in turn, impacts on performance and the achievement of organisational goals. The symptoms of these problems result in low productivity, high absenteeism, labour unrest, industrial action and high labour turnover. The current situation in the public sector in South Africa is not dissimilar. Public sector employees are faced with a multitude of factors that impact on effective and efficient service delivery.

The study investigates how employees discern workforce diversity and the possible effect that diversity can have on their satisfaction at work.

\section{Problem Statement}

According to Nelson \& Quick, (1997) the South African workplace today is made up of different employees with unique (diverse) characteristics. Does this situation affect the way employees feel about their jobs? Moreover, many organizations in the new South Africa now engage different workers in their workforce to improve their image as they promote "Affirmative action" in line with South African government policy (Cavaleros Vooren \& Delene, 2002). To work effectively with diverse people, managers need to know not only about the persons with whom they interact, but also their personality, behavior patterns in conflict situations, demographics and life experiences. The question that still remains unanswered is how employees feel about diversity in their working environments and whether workplace diversity results in dissatisfaction or anxiety and whether or not that may result in losses of productivity. Since most studies have been focusing on workforce diversity rather than discernments of employees in the workplace, this study focused on employees' discernment of workforce diversity and its effect on job satisfaction in the context of a selected public service 
department.

\section{Objectives of the Study}

* To identify the employees' discernment of workforce diversity.

* To examine the extent to which the current state of diversity in the workplace is related to employees' job satisfaction.

* To provide recommendations for management actions implemented in organizations to avoid problems caused by diversity.

\section{Research Hypotheses}

In view of the statement of the problem it is hypothesised that:

1. H1: Attitudes towards workforce diversity are positively related to job satisfaction.

2. H2: The existence of workforce diversity management programmes is positively correlated with job satisfaction.

HO: The existence of workforce diversity management programmes is not positively correlated with job satisfaction

\section{Theoretical Framework}

\subsection{Similarity/Attraction Theory}

The study made use of the Similarity/Attraction Theory; the similarity/attraction stream of research is predicated on the notion that similarity in attributes, particularly demographic ones, increases interpersonal attraction and liking (Pitts \& Jarry, 2006).

Individuals with similar backgrounds may find that they have more in common with each other than with those from different backgrounds, making it more comfortable for them to work together and collaborate in producing a product or solving a problem. Similarity allows one to have his or her values and ideas reinforced, whereas dissimilarity causes one to question his or her values and ideas, a process that is likely to be unsettling. Previous research has shown that in a situation where an individual has the opportunity to interact with one of a number of different people, he or she is most likely to select a person who is similar (Pitts \& Jarry, 2006).

That one is likely to be most attracted to those with similar attributes yields clear predictions for the relationship between organizational diversity and work-related outcomes. Previous research using the similarity/attraction concept found that dissimilarity led to a lack of "attraction" to others that manifested itself in decreased communication, message distortion, and communication error Nelson \& Quick, (1997). Similarity/attraction theory predicts that high levels of diversity in an organization or in a work group are likely to lead to faulty work processes. These faulty work processes will, in turn, lead to job dissatisfaction and poor performance.

\subsection{Literature review}

\subsubsection{Workforce diversity}

According to Cavaleros, et al. (2002) diversity refers to differences between people in organizations. To define diversity more specifically is a daunting task because there are many differences between people at work, including differences in race, gender, ethnicity, personality, tenure, organizational function etc. There is also the fact that diversity not only involves how people think of others and how this affects their interaction, but how they conceive of themselves. Cavaleros, et al. (2002) suggests that one way to approach the question is to consider "whether diversity should be broadly defined or narrowly defined". A broad definition would see diversity as including all possible ways in which members of work teams may differ. It would consider differences of race, gender, age and other demographic categories as essentially the same as differences in values, attitudes, organizational functions, tenure and personality.

Diversity may also refer to "otherness". As Nelson \& Quick, (1997) observe diversity may not only be looked at in terms of simply human differences, but it can be broken down into primary and secondary dimensions. Primary dimensions are those of age, ethnicity, gender, physical abilities, race and sexual orientation, while secondary dimensions cover such as those that can be changed. These include educational background, geographical location, 
marital status religion and others. Grobler, Warnich, Carrel, Elbert \& Hartfield (2002) in their view of diversity in the South African context, stresses that the change in the demographic structure of the South African workforce now mirrors the diversity of the South African population as a whole. In other studies Grobler et al. (2002) point to six major aspects that make for diversity in the South African workplace, namely; ethnic groups, gender, young workers, South Africans with disabilities, sexual orientation and culture.

\subsubsection{Ethnic groups}

The South African population is comprised of four ethnic groups, blacks, colored, Asians and whites. To complicate matters further, more than 11 languages are spoken across these groups. This state of ethnical differences highlights the complications that may arise because of these differences (Grobler et al. 2002).

\subsubsection{Gender}

A greater number of women in the workforce do offset the decline in the number of male workers. Nevertheless, female workers are still not welcomed, by many employers, in top management positions. Preliminary surveys of the private sector show that one in four positions there are held by women as compared with almost two out of three positions in the public sector Grobler et al. (2002). Most male employees are still not very comfortable with women in the workplace, especially in managerial positions.

\subsubsection{Age}

According to Grobler et al. (2002) South Africa has a relatively young population; more than $62 \%$ are younger than 30 years of age. This differs from most western countries, where the majority of the workplace is comprised of middle aged and older working groups. The main cause is that South Africa is a developing country that has to invest in a young workforce. It does mean that tenured (older) employees may feel threatened by an increasingly younger workforce and fear to lose their jobs. Workplace age stereotypes are beliefs and expectations about workers based on their age. Often these stereotypes are negative, inaccurate, or distorted opinions about people based on their membership in a particular age group. They may be based on hearsay, preconceived ideas, or unfounded assumptions and incorrectly infer that all members of such group are the same (Grobler et al. 2002).

\subsubsection{Disabled workers in South Africa}

Common disabilities in South Africa include hearing and sight impairments, physical disabilities, mental or emotional deficiency and various nerve disorders. Many individuals according to Grobler et al. (2002) experience anxiety around disabled workers especially if the disability is severe. However, the manager can set the tone for proper treatment of workers with disabilities. This is important as people with disabilities now fall within the so-called "designated groups" identified by the South African Employment Equity Act (EEA) 55 of 1998. This Act open ways for all South Africans and is against any form of discrimination against employees. Even so, most workers are still uncomfortable working with disabled co-workers, and this can lead to increased dissatisfaction unless all workers are taught to work with disabled coworkers.

\subsubsection{Sexual orientation}

According to Stats-SA (1999) 10\% of the population in South Africa is homosexual. This therefore means that $10 \%$ of men and women in the workplace are "gay". The South African government's acceptance of all "gay" people as normal does not mean that most workers in South African organizations are comfortable working with gay co-workers (www.stassa.co.za).

\subsubsection{Cultural knowledge}

According to Van Niekerk, (2004) Cultural knowledge is a deep understanding of the beliefs, customs and traditions of cultures and a fundamental building block in relationships, including work relationships. Consequently, a management style should result in a manager being aware of the prevailing cultures in the organization. For cultural diversity it makes 
good sense for companies to alter their racial and gender mix so as to mirror the general population, or their customer base. Employment equity laws do force the pace of transformation, but while we are told that diversity in the workplace is good and that organizations benefit from it, tensions will be inevitable as organizations battle to get the best from their increasingly diverse workplaces. Lack of trust in cultural diversity is a massive problem in South Africa. Where trust exists, people talk to each other, share ideas and are respectful. Where trust is missing, toxic behavior becomes the norm (Van Niekerk, 2000).

\subsubsection{Job satisfaction in the working environment}

Prolific research in the area of job satisfaction has been conducted over the past few decades (Boshoff, Cilliers \& Van Wyk, 2003; Buitendach \& De Witte, 2005; Calder, 2000; Derlin \& Schneider, 1994; Dolliver, 2003; Hoole \& Vermeulen, 2003; Kh Metle, 2005; Malherbe \& Pearse, 2003). However, a paucity of studies exist in the public health industry investigating job satisfaction across different occupational classes. The vast majority of studies conducted in the public health industry in South Africa over the past years have mainly focused on job satisfaction amongst health care doctors and nurses (Damane, 1992; Herman, 2005; Mariani, Gcaba \& Dalton, 2003; Mavanyisi, 2005; Pillay, 2003).

\subsubsection{Theory and studies of employee job satisfaction}

Job satisfaction in one form or another has been related to such variables as turnover, absenteeism, productivity, group cohesiveness, general hygiene factors, job rewards, personal rights, labor unrest and performance appraisals. These dependent variables have monetary implications for organizations and therefore research on employee satisfaction is very important. In South Africa political change and frequent labor unrest necessitates a closer look at awareness of employees and their level of satisfaction Visser \& Breed (1997).

There is no single commonly agreed shared theory of job (employee) satisfaction. For the purposes of this study, Hertzberg's two factor motivational theory will be used to show that elements that bring satisfaction simply refer to the positive/negative reactions of people to their jobs (www.coe.iup.edu). According to Cavalores et al. (2002) job satisfaction may be defined as an individual's general attitude towards his/her job. Visser \& Breed (1997) further indicates that a person with a high level of job satisfaction holds positive attitudes towards the job, while a person who is dissatisfied with his/her job holds negative attitudes about it.

Visser \& Breed (1997) argues that a person's job is more than just the obvious activities of shuffling papers, waiting on customers or driving a truck. Rather, jobs include interaction with co-workers and bosses, following organizational rules and policies, meeting performance standards, living with working conditions that are often less than ideal and the like. In addition, Fitz-enz (2002) emphases that an employee's assessment of how he/she is satisfied or dissatisfied with their job is a global summation of a number of discrete job elements.

Hertzberg was the first researcher to show that satisfaction and dissatisfaction at work nearly always arises from different kinds of factors. Hertzberg showed that certain factors truly motivate (motivators) whereas others tend to lead to dissatisfaction (hygiene factors). Accordingly Hertzberg developed the motivation-hygiene theory (www.net.mba.com).

In developing Fitz-enz (2002) pointed to six main factors causing dissatisfaction. These are company policy, supervision, relationship with the boss, working conditions, salary and relationship with peers satisfaction, by contrast is caused by recognition, the work itself, responsibility, advancement and growth. Robbins Odendaal \& Roodt (2004) replicated Hertzberg's theory for the South African context. The results of their study showed that similar motivators and hygiene factors were causing satisfaction and dissatisfaction respectively for both the white and black schooled population. For the unschooled black, satisfaction and dissatisfaction were caused mainly by the hygiene factors because they had no exposure to motivators.

\subsection{The link between job satisfaction (Hertzberg's theory) and workforce diversity}

Job satisfaction was earlier defined as an individual's cognitive, affective and evaluation reaction to their jobs. As indicated by Nel, Van Dyk, Schultz \& Werner (2004), job satisfaction influences absenteeism, labor turnover, commitment and organizational citizenship. This brings to mind, Hertzberg's two-factor motivational theory as different factors and differences among people in the organization can make people feel exceptionally good or bad about their jobs.

Cavaleros et al. (2002) show that diversity in the work situation encompasses every individual difference that affects a task relationship; this can mean that people may want different supervision, working conditions or even have different attitudes towards their bosses because of their diverse characteristics. Robbins et al. (2004) conducted studies 
in South African organizations to see how satisfied/dissatisfied employees were about their jobs, making use of the following diverse characteristics: age, gender, marital status and tenure.

\subsubsection{Age}

Robbins et al. (2004) found that senior employees are more satisfied with their jobs and more steady and productive. This issue is now under the spot-light because young employees have now made it into the workplace.

\subsubsection{Gender}

There has been an influx of women into the South African labor force over the past 30 years. Recent statistics (2001) showed that women constitute $42.8 \%$ of the workforce and experience a high level of satisfaction at work (Robbins et al. 2004). The study will make use of these statistics in investigating whether it is true that most of the male workers are dissatisfied with the current statistics of women in the workplace. In addition, women are complaining that most organizations place men in managerial positions and women in lower level positions (glass ceiling); hence this study will generate ways in which managers should manage workforce diversity and look at the importance of workforce diversity in the workplace.

\subsubsection{Marital status}

Indications on marital status are that married employees are les absent, contribute less to turnover and are more satisfied with their jobs as compared to unmarried co-workers (Robbins et al. 2004).

\subsubsection{Tenure}

Robbins et al. (2004) argued that tenure is inversely related to absenteeism and that there is a positive relationship between tenure and job satisfaction. Nevertheless, there are many diverse characteristics of employees that may bring some changes in these results. The above results demonstrate that employees may feel differently about their jobs because of diverse characteristic they have. Nelson \& Quick (1997) explain that Hertzberg's theory distinguishes between intrinsic and extrinsic factors. Intrinsic factors include advancements and achievements and are related to job satisfaction. In their study Nelson \& Quick (1997) include intrinsic political affiliation among the factors as subtle but powerful force in the diversity stakes. Black employees in South Africa are advancing to higher positions and as a result they can be called achievers. This is supported by the Employment Equity Act 55 of 1998. This brings satisfaction for blacks, while about $14.7 \%$ of whites have left the labor force because of the current political environment in South Africa (www.stats.sa.com).

Job satisfaction can be broken down into two main groups of factors contributing to satisfaction/dissatisfaction of employees, namely, personal and organizational factors. Personal factors refer to personality, status, seniority and general life satisfaction which are all different diverse characteristics of individuals and can be associated with the motivators of Hertzberg's motivational theory. According to Nel et al. (2004) organizational factors include pay and benefit, supervisor, relationship with co-workers and working conditions that may all be classified as hygiene factors, according to Hertzberg. Both the personal and organizational factors contribute to the level of satisfaction or dissatisfaction amongst employees. Diversity can influence attitudes towards work negatively or positively and contribute to either satisfaction or dissatisfaction on the job.

\section{Research Methodology}

\subsection{Population and sample of the study}

According to Kruger, Michell \& Welman (2005) population is the study object and consists of individuals, groups, organizations, human products and events or the conditions to which they are exposed. Population encompasses the total collection of units of analysis about which the researcher wishes to make specific conclusions. The target population of this study is all employees in the Public Service Department and this is 90 in total.

The sample size used was calculated using the Raosoft Sample Size Calculator. Sample size is a function of three factors - the significance level, power, and magnitude of the difference (effect size).

The sample size $n$ and margin of error $E$ are given by: 


\section{$x=Z(c / 100) 2 r(100-r)$}

$\mathrm{n}=\mathrm{N} \mathrm{Xl}((\mathrm{N}-1) \mathrm{E} 2+\mathrm{x})$

$E=S q r t[(N-n) x / n(N-1)]$

Where $N$ is the population size, $r$ is the fraction of responses that you are interested in, and $Z(c / 100)$ is the critical value for the confidence level c. Using 7\% margin of error, $90 \%$ confidence level and an expected response distribution of $50 \%$, a minimum recommended sample size of 90 respondents was determined. Therefore, in this research, 90 employees in the Public Service Department and were considered as representative of the entire population.

\subsection{Sample size and Sampling Procedure}

According to Fouche, Delport \& Strydom, (2005) probability sampling is one in which each person or other sampling unit in the population has the same known probability of being selected. This study made use of the probability sampling procedure in which every element in the population has a known chance of being selected in the sample since probability sampling procedures allow for generalisation to the entire population. In this study, respondents were randomly selected within the Department. The advantage of using this sampling method is that it has the least bias and offers optimal generalisability.

\subsection{Research Design}

Research design refers to the steps that researchers follow to complete their study from start to finish. It includes asking research questions based on theoretical orientation, selection of respondents, data collection and reporting of the results (Marvasti, 2004). In addition, it provides the overall structure of the procedures that the researcher follows, the data that the researcher collects and the data analysis that the researcher conducts. The methodology to be used for a particular research problem must always take into consideration the nature of the data that will be collected in the resolution of the problem, thus the data dictate the research method.

This study utilized a quantitative design. This type of research involves either identifying the characteristics of observed phenomenon or exploring possible correlations among two or more phenomena. In every case descriptive research examines a situation as it is, does not change or modify the situation nor does it intend to detect cause and effect relationships (Marvasti, 2004).

\section{Data Collection}

The study used questionnaires to gather data from the staff members of the Public Service Department). Nachmias \& Nachmias (2000) define a questionnaire as a list of questions that must be formulated, constructed and sequenced to produce the most constructive data in the most effective manner. The study made use of closed- ended questions which consisted of statements and were divided into five sections on a Likert scale. Closed-ended questions provide a set of predetermined answers from which the respondents have to choose applicable answers (Fouche et al. 2005).

Questionnaires also standardise the questions and response categories such that every participant responds to identical stimuli in determining the employees' discernment of workforce diversity and its effect on job satisfaction. Questionnaires were self-administered. The main advantage of this method is that the researcher can collect all the completed responses within a short period of time. Any doubts that the respondents might have on any question could be clarified on the spot. Moreover, the researcher is afforded the opportunity to introduce the research topic and motivate the respondents to offer their frank answers. It is also a less expensive method.

\section{Data Analysis}

Techniques used during data analysis included descriptive statistics in which participants' responses were described in detail. Participants were studied and those with similar responses were grouped together and coded. According to Fouche et al. (2005) data analysis involves methods that help to describe facts, and develop explanations. The purpose of analysis is to reduce data to an intelligible and interpretable form so that the relations of research problems can be studied and conclusions drawn. This study made use of descriptive research to establish employees' discernment of workforce diversity and its effect on job satisfaction in the Public Service Department. 


\section{Research Findings and Discussion}

\subsection{Descriptive statistics on demographical Information}

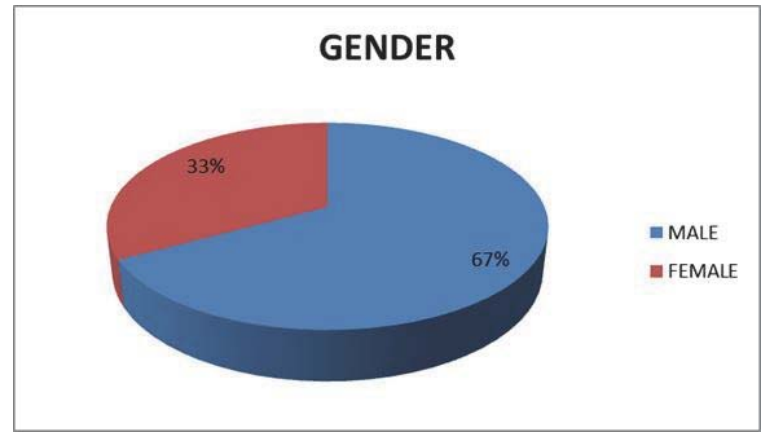

Figure 1: Responses according to gender

\begin{tabular}{ccccc}
\hline Gender & Frequency & Percentage (\%) & Valid Percentage (\%) & Cummulative Percentage \\
\hline Male & 60 & 66.7 & 66.7 & 66.7 \\
Female & 30 & 33.3 & 33.3 & 100.0 \\
Total & 90 & 100.0 & 100.0 & \\
\hline
\end{tabular}

Table 1: Gender distribution

Figure 1 and table 1 indicate that there was a lower representation of female respondents (30 or 33.3\%), male respondents constituting the majority (60 or $66.7 \%$ ).

9.2 Distribution of respondents by marital status

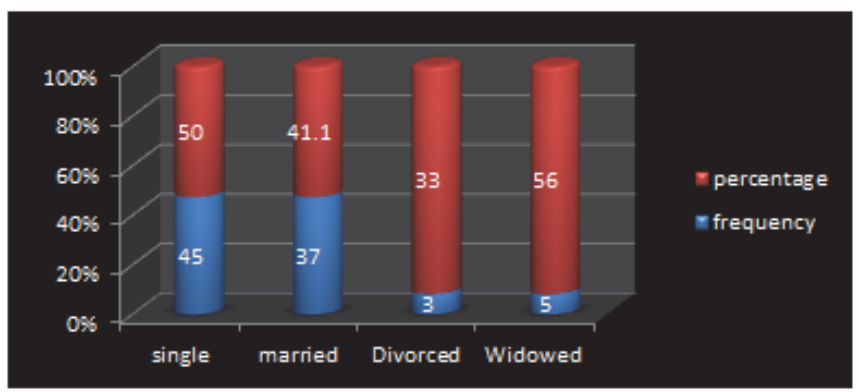

Figure 2: distribution of respondents by marital status

As depicted in Figure 2 a large number, (45 or $50 \%$ ) of respondents were single, there being (37 or $41 \%)$ married respondents. Divorced respondents were (3 or $3.3 \%$ ) while widowed respondents were (5 or 5.6\%). Divorced employees constituted the smallest category by marital status. 


\subsection{Distribution of respondents by age}

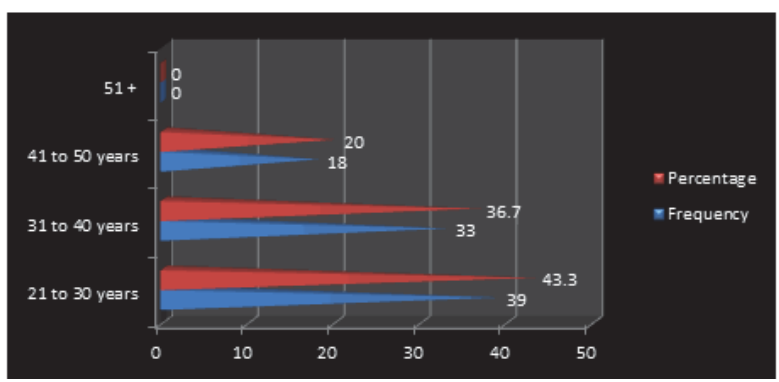

Figure 3: Distribution of respondents by age

Figure 3 indicates that most respondents were between the ages of 21-30 (43\%). Employees between the ages of 31-40 were $33(36.7 \%)$ and the age groups between $41-50$ years were $18(20.0 \%)$. No respondents were older than 50 . The results show that the Department of Local Government and Traditional Affairs is representative of the young employees.

\subsection{Distribution of respondents by ethnic groups}

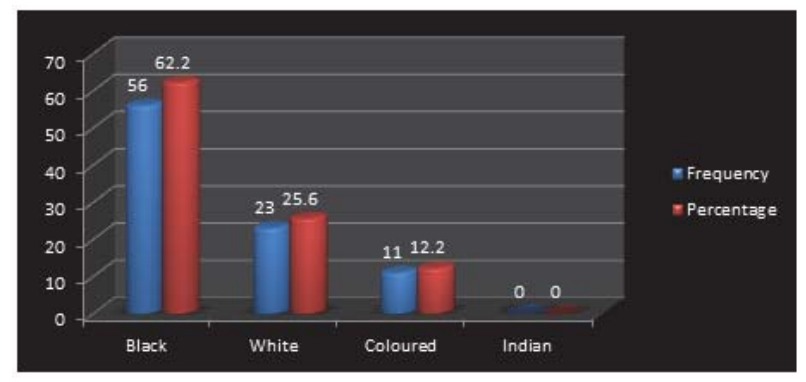

Figure 4: Distribution of respondents by ethnic groups

The ethnicity of respondents was important to the study since the ethnicity that one holds influences discernments of workforce diversity and job satisfaction. Figure 4 reveals that 56 (62.2\%) of the respondents were black. $23(25.6 \%)$ were whites, while coloured respondents were 11 (12.2\%). There were no Indian respondents or respondents from any other ethnic background. Most respondents were black.

\subsection{Distribution of respondents by income levels}

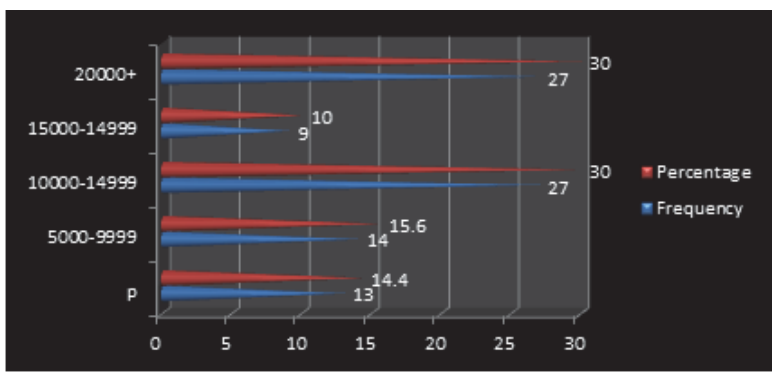

Figure 5: Distribution of respondents by income levels 
As depicted in figure 5 a large number of respondents enjoyed a monthly income between R10000-14999 and more (30\%). Respondents with an income of R0-4999 were13 (14.4\%) and respondents with an income of R15000-19999 were $9(10.0 \%)$, the smallest group.

\subsection{Distribution of respondents by period of service}

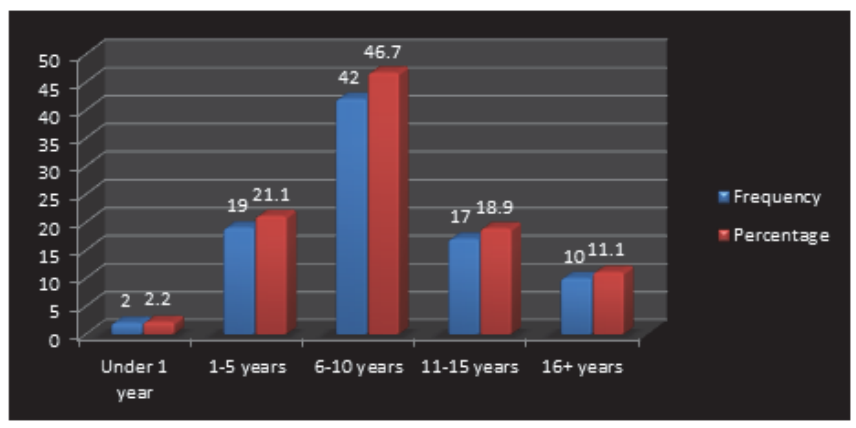

Figure 6: Distribution of respondents by period of service

Figure 6 reflects number of respondents by length of service. Respondents with 6-10 years of service were in the majority, $42(46.7 \%)$. Respondents with 1-5 years of service were 19 (21.1\%), and employees with 11-15 years of service were $17(18.9 \%)$. Respondents with $16+$ years of service were $10(11.1 \%)$. The smallest group of respondents had less than 1 year of service, $2(2.2 \%)$.

\subsection{Distribution of respondents by professional qualification}

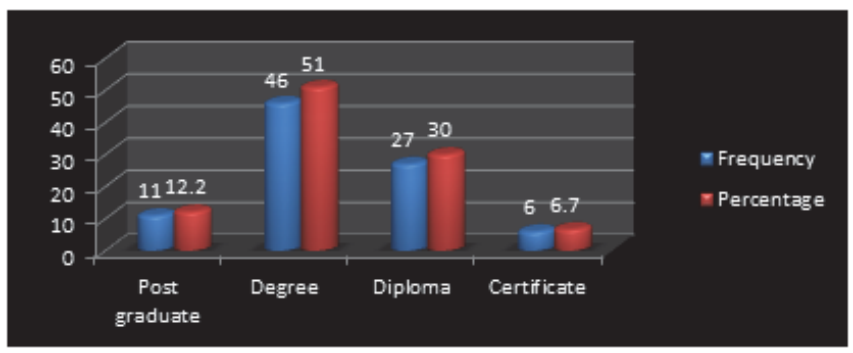

Figure 7: Distribution of respondents by professional qualification

As shown in figure 5.7, $46(51 \%)$ of respondents hold degrees, while respondents with diplomas were $27(30.0 \%)$. Respondents with post graduate qualifications were $11(12.2 \%)$. Respondents with a certificate qualification were the smallest group, totaling $6(6.7 \%)$. The majority of respondents are highly qualified. 


\subsection{Distribution of respondents by job title}

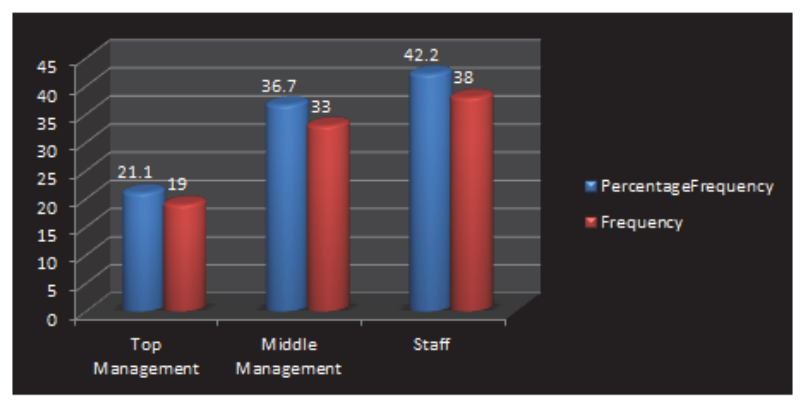

Figure 8: Distribution of respondents by job title

As depicted in figure $8,38(42.2 \%)$ of respondents were staff, 33 (36.7\%) were in middle management. The smallest group of respondents was in top management, namely 19 (21\%). The results show that the majority of respondents were staff.

\section{Discernments of respondents of workforce diversity in the workplace and its effect on job satisfaction}

Table 2: Discernments of respondents of workforce diversity in the workplace and its effect on job satisfaction

\begin{tabular}{|c|c|c|c|}
\hline \multirow{4}{*}{ Workforce Diversity } & & Job satisfaction & Job satisfaction \\
\hline & Pearson Correlation & $.306^{*}$ & $.682^{* *}$ \\
\hline & Sig. (2-tailed) & .003 & .002 \\
\hline & N & 90 & 90 \\
\hline & Pearson Correlation & .642 & (634 -6 \\
\hline \multirow[t]{4}{*}{ Ethnicity } & Sig. (2-tailed) & .328 & .426 \\
\hline & $\mathrm{N}$ & 90 & 90 \\
\hline & & Job satisfaction & Job satisfaction Commitment \\
\hline & Pearson Correlation &.$-301^{*}$ & $.582^{* *}$ \\
\hline \multirow[t]{3}{*}{ Gender } & Sig. (2-tailed) & .008 & .006 \\
\hline & $\mathrm{N}$ & 90 & 90 \\
\hline & Pearson Correlation & .642 & .644 \\
\hline \multirow[t]{4}{*}{ Age } & Sig. (2-tailed) & .308 & .416 \\
\hline & $\mathrm{N}$ & 90 & 90 \\
\hline & & Job satisfaction & Job satisfaction \\
\hline & Pearson Correlation & $.328^{*}$ & $.872^{* *}$ \\
\hline \multirow[t]{3}{*}{ Disability } & Sig. (2-tailed) & .003 & .003 \\
\hline & $\mathrm{N}$ & 90 & 90 \\
\hline & Pearson Correlation & .642 & .634 \\
\hline \multirow[t]{2}{*}{ Sexual orientation } & Sig. (2-tailed) & . -328 & .466 \\
\hline & $\mathrm{N}$ & 90 & 90 \\
\hline
\end{tabular}

In testing hypothesis 1 which stated that attitudes towards workforce diversity are positively related to job satisfaction, table 1 above presents the results of the relationships. Significant positive relationship was obtained between the transformational leadership style and affective commitment ( $r=.306, p=.003)$.

The study utilized the Pearson Correlation Method to identify whether there is a negative or positive correlation between attitudes towards workforce diversity and job satisfaction and whether the existence of workforce diversity management programmes are positively or negatively correlated with job satisfaction. There is a negative correlation between ethnicity and job satisfaction, also a negative correlation between gender and job satisfaction. (Male workers have negative attitudes towards working with female employees, because they see them as incompetent and unable to handle stress). 
There is a however, positive correlation between age and job satisfaction. It also shows that there is a positive correlation between disabled employees and job satisfaction. The more disabled workers there are in an organization the more dissatisfied are the employees. There is a positive correlation between sexual orientation and job satisfaction. Employees have a negative attitude to working with homosexuals and this negatively affects their satisfaction and could lead to a high rate of absenteeism. The results therefore reject the alternative hypothesis which is; attitudes towards workforce diversity are positively related to job satisfaction.

H1: Attitudes towards workforce diversity are positively related to job satisfaction.

$\mathrm{H} 2$ : The existence of workforce diversity management programmes are positively correlated with job satisfaction.

HO: The existence of workforce diversity management programmes are not positively correlated with job satisfaction.

There is an insignificant correlation between diversity management programmes and job satisfaction (Hypothesis 2). Employees are not provided with diversity workshops. These workshops might improve the existing state of diversity and increase job satisfaction among employees. Moreover, there is an insignificant correlation between diversity training programmes and job satisfaction. There is a lack of diversity training of employees and this results to a tension among employees because they are not aware of diversity. The results therefore reject the alternative hypothesis which is the existence of workforce diversity management programmes are positively correlated with job satisfaction.

\section{Conclusions and Recommendations}

Most organizations today engage in diversity processes without properly informing their employees; moreover, the views of employees during the implementation and training process are hardly considered. It is important for organizations to always include their employees whenever they plan for diversity. This may reduce resistance, absenteeism and dissatisfaction among employees. Although the respondents see workforce diversity as a threat, some employees simply see diversity as beneficial to the organization while their interests are not being considered. This might be caused by failure of management to fully inform all employees about the why, the scope and the benefits of workforce diversity both for the employees and the organization. Even though workforce diversity is considered to be beneficial if well managed, most employees see workforce diversity as a threat in working relationships, and as damaging for both morale and productivity.

The study demonstrates the need for the organization to provide adequate support in the establishment of workforce diversity programmes, diversity training and implementation processes. Regardless of the workforce diversity process, most of the staff and middle management employees showed a high level of dissatisfaction. By contrast, top management staff reveals high satisfaction and see the diverse workforce as highly beneficial to the survival of the organization. The study has shown that the majority of employees experience dissatisfaction, probably because of mismanagement of diversity and lack of awareness programmes being offered by the organization.

Emanating from the conclusions listed above, the following recommendations can be made: It is imperative for management to always fully include their employees during diversity processes (diversity training and implementation processes). Management must understand discrimination and its consequences. This will eliminate discrimination in the workplace hence it is important to understand discrimination and; as per the Employment Equity Act of (1995). Managers should promote a "safe" place for employees to communicate in social gatherings and business meetings. Communicating in social gatherings plays a vital role because employees will get to know each other better and they can even share their ideas on a particular subject on problems they encounter in the workplace.

Managers should implement mentoring programs to provide employees with access to information and opportunities. Managers should not just implement policies; they should monitor them in terms of progress. This monitoring will help them identify employees who have negative attitudes towards diversity. Managers should treat all employees equally. If managers fail to treat its workforce equally it will create a negative attitude among employees and this could have a negative effect on job satisfaction. Management should implement diversity training and awareness programmes. These diversity trainings and awareness programmes will help employees to adapt to diversity and they will be aware of benefits, but also of weaknesses if not well managed. Managers should communicate clear diversity utilisation strategy and expectations. These expectations will help the employees to know what is expected of them and in return managers will also have a clear understanding of employee expectations. Management must control their attitudes and must not favour some of the employees due to the influence of diversity. Employees on the other hand should accept the existing state of affairs and try to cooperate and support each other regardless of their differences. 


\section{References}

Boshoff, A.B., Cilliers, F.V.N., \& Van Wyk, R. (2003). The prediction of job involvement for pharmacists and accountants. South African Journal of Industrial Psychology, 29(3), 61-67.

Buitendach, J.H., \& De Witte, H. (2005). Job insecurity, extrinsic and intrinsic job satisfaction and affective organisational commitment of maintenance workers in a parastatal. South African Journal of Business Management, 36(2), 27-37.

Calder, G. (2000). Motivating pharmacist [Electronic version]. The Pharmaceutical Journal, 7096(264), 729-731.

Cavaleros, C., Vooren, V.V. \& Delene, D. 2002. The effectiveness of diversity awareness training programme. South African Journal of Industrial Psychology, Vol 28(3):50-61.

Damane, T.V.P. (1992). Factors influencing job satisfaction or dissatisfaction among female registered nurses employed by the department of Health, Transkei. Unpublished master's thesis, University of Natal, Durban.

Derlin, R., \& Schneider, G.T. (1994). Understanding job satisfaction: Principals and teachers, urban and suburban. Urban Education, 29(1), 26

Dolliver, M. (2003). Job satisfaction. Adweek, 44(38), 38.

Fitz-enz, J. 2002. How to measure Human Resource Management. 3rd Ed. New York: McGraw-Hill.

Fouche, C.B., Delport, C.S.C. \& Strydom, H. 2005. Research at Grass roots. 3rd ed. Pretoria: Van Schaik Publishers.

Grobler, P.A., Warnich, S., Carrel, M.R., Elbert, N.F. \& Hartfield, 2002. Human Resource Management in South Africa. 2nd ed. Manitoba: Thomson Learnings.

Herman, D. (2005, August 8). Children wait for ops as Red Cross short of ICU nurses. Cape Times, p. 5.

Hoole, C., \& Vermeulen, L.P. (2003). Job satisfaction among South African aircraft pilots [Electronic version]. SA Journal of Industrial Psychology, 29(1), 52-57.

http//www.statssa.co.za) Accessed on 6 March 2006.

$\mathrm{Kh}$ Metle, M. (2005). Age-related differences in work attitudes and behavior among Kuwaiti women employees in the public sector [Electronic version]. International Journal of Commerce and Management, 15(1), 47-67.

Kruger, A.L., Michell, B. \& Welman, S. 2005. Research Methodology. 3rd ed. South Africa: Oxford University Press.

Malherbe, M.D., \& Pearse, N.J. (2003). The relationships between job enrichment, job satisfaction and service quality: An exploratory study in the retail industry in South Africa. Management Dynamics, 12(2), 2-12.

Mariani, D., Gcaba, R., \& Dalton, J. (2003). Survey on knowledge, attitude and practice (KAP) on professional nurses working at primary health care level. Retrieved February 20, 2005, from: http://www.kznhealth.gov.za/italian/kapsyrvey.pdf

Mavanyisi, R.D. (2005). The perceptions of nurses in a district health system in Limpopo province on job satisfaction.

Unpublished master's thesis, UNISA, South Africa.

Mavarsti, A.B. (2004). Qualitative research in Sociology. London: Sage.

Meyer, M. (1999). Managing human resources development - An outcomes-based approach. Durban: Butterworth Publishers (Pty) Ltd.

Nachmias, C.F. \& Nachmias, D. (2000). Research Methods in the Social Sciences, 6th Ed. New York: St Martin's Press.

Nel, S. Van Dyk, P. Schultz, B. \& Werner, A. 2004. Human Resource Management. 3rd ed. South Africa: Oxford University Press.

Nelson, D.L \& Quick, L. C 1997. Organizational Behavior: foundations, realities and challenges. Minneapolis: West Publications. Inc.

Pillay, R. (2003). The effect of organisational structure and managerial practices on the clinical behaviour and job satisfaction of primary health care doctors, as knowledge workers in the managed health care industry in South Africa. Unpublished doctoral thesis, University of Cape Town, Cape Town.

Pitts, D. \& Jarry, E. M. Ethnic Diversity and Organizational Performance: Assessing Diversity Effects at the Managerial and Street Levels. http://aysps.gsu.edu/publicatio ns/2006/index.htm.

Robbins, S.P. Odendaal, A. \& Roodt, G. 2004. Organizational Behavior (Global and Southern African Perspectives). 7nth ed. South Africa: Pearson Education Inc.

RSA (Republic of South Africa). 1998. Employment Equity Act, No.55 of 1998. Government Gazette, No.20626. Government Printer, Pretoria.

Strydom, J.B. 1998. Diversity management in South African organizations. Journal of Industrial Psychology, Vol 24- 25 (2): 9-15.

Van Niekerk, A.A. 2004. The effect of cultural diversity in the workplace: Journal of Business and Psychology, Vol 18, No 3.

Visser, P.J. \& Breed, M. 1997. A triangulation approach. Journal of Industrial Psychology, Vol 22-23 (13): 23-27. 